Issued by Sandia National Laboratories, operated for the United States Department of Energy by Sandia Corporation.

NOTICE: This report was prepared as an account of work sponsored by an agency of the United States Government. Neither the United States Government, nor any agency thereof, nor any of their employees, nor any of their contractors, subcontractors, or their employees, make any warranty, express or implied, or assume any legal liability or responsibility for the accuracy, completeness, or usefulness of any information, apparatus, product, or process disclosed, or represent that its use would not infringe privately owned rights. Reference herein to any specific commercial product, process, or service by trade name, trademark, manufacturer, or otherwise, does not necessarily constitute or imply its endorsement, recommendation, or favoring by the United States Government, any agency thereof, or any of their contractors or subcontractors. The views and opinions expressed herein do not necessarily state or reflect those of the United States Government, any agency thereof, or any of their contractors.

Printed in the United States of America. This report has been reproduced directly from the best available copy.

Available to $\mathrm{DOE}$ and $\mathrm{DOE}$ contractors from

Office of Scientific and Technical Information

P.O. Box 62

Oak Ridge, TN 37831

Prices available from (703) 605-6000

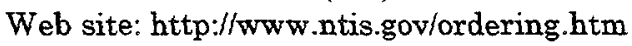

Available to the public from

National Technical Information Service

U.S. Department of Commerce

5285 Port Royal Rd

Springfield, VA 22161

NTIS price codes

Printed copy: A03

Microfiche copy: A01

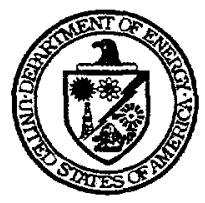




\section{DISCLAIMER}

Portions of this document may be illegible in electronic image products. Images are produced from the best available original document. 
SAND2000-8600

Unlimited Release

Printed April 2000

\title{
Experimental Measurements of the Thermal Conductivity of Ash Deposits: Part 2. Effects of Sintering and Deposit Microstructure
}

\author{
Allen L. Robinson", Steven G. Buckley ${ }^{\dagger}$, Nancy Yang, and Larry L. Baxter \\ Combustion Research Facility \\ Sandia National Laboratories \\ Livermore, CA 94551-0969
}

\section{Abstract}

We report results from an experimental study that examines the influence of sintering and microstructure on ash deposit thermal conductivity. The measurements are made using a technique developed to make in situ, time-resolved measurements of the effective thermal conductivity of ash deposits formed under conditions that closely replicate those found in the convective pass of a commercial boiler. The technique is designed to minimize the disturbance of the natural deposit microstructure. The initial stages of sintering and densification are accompanied by an increase in deposit thermal conductivity. Subsequent sintering continues to densify the deposit, but has little effect on deposit thermal conductivity. SEM analyses indicates that sintering creates a layered deposit structure with a relatively unsintered innermost layer. We hypothesize that this unsintered layer largely determines the overall deposit thermal conductivity. A theoretical model that treats a deposit as a two-layered material predicts the observed trends in thermal conductivity.

\footnotetext{
* Corresponding author. Currently at the Dept. of Mechanical Engineering and the Dept. of Engineering and Public Policy, Carnegie Mellon University, Pittsburgh, PA 15213. (412) 268-3657. alr@andrew.cmu.edu.

' Currently at the Department of Mechanical Engineering, 2181 Glenn L. Martin Building, University of Maryland, College Park, MD 20742
} 
This page intentionally left blank 


\section{Introduction}

Ash deposits reduce heat transfer rates to furnace walls, superheater tubes, and other heat transfer surfaces in coal-fired power plants. The magnitude of this reduction largely depends on the thickness, thermal conductivity, and emissivity of the deposits. This paper examines the thermal conductivity of ash deposits under conditions similar to those found in the convective pass of utility-scale boilers; recent reviews document the current theoretical and experimental state of the art 1,2 .

Ash deposits are a complex, heterogeneous, multiphase, porous material. An extensive literature exists that discusses the heat transfer characteristics of porous materials (see, e.g., 3,4 ). Like many porous materials at high temperature, both conduction and radiation can contribute to the overall heat transfer rate through the deposit; therefore, we use the effective thermal conductivity to characterize the overall heat transfer rate. The effective thermal conductivity is a lumped parameter that accounts for heat transfer by all these different modes; in this paper, the phrase "thermal conductivity" refers to the effective thermal conductivity of the deposit.

The transport properties of ash deposits and other porous materials are thought to depend strongly on the deposit physical structure or microstructure 1,4,5. Ash deposits have a complex, highly three-dimensional microstructure. The initial structure is determined by several competing mechanisms that control deposition 6 . The deposit structure then changes on time scales ranging from minutes to days due to sintering and chemical reactions occurring at high temperature within the deposit.

Although numerous investigations report measurements of the thermal conductivity of ash deposits 1,7-11, little experimental data exist to define quantitatively the relationship between deposit microstructure and thermal conductivity. As discussed in the first part of this investigation 12 , the previous measurements were made on highly processed and disturbed ash samples whose microstructure may not be representative of actual boiler deposits. Second, little data are presented that describe the microstructure of the materials that were examined. Characterizing deposit microstructure is very difficult; we are aware of only two published papers that present quantitative measurements of ash deposit microstructure 13,14 . 
The lack of experimental data on deposit thermal conductivity and microstructure has hampered the development of realistic models for deposit thermal conductivity. Ash deposit property models are needed to simulate the effects of ash deposition on boiler performance. Existing boiler models rely on empirical expressions for evaluating deposit thermal conductivity $15-20$. The simplest treatments assume a constant value for deposit thermal conductivity 15,18; more sophisticated approaches employ fits of experimental data 19,20 . Frequently the data used to determine the deposit thermal conductivity are based on measurements of surrogate materials such as sandstone and not the reported ash deposit data 15,20 .

In this two-part study, we report an experimental investigation into the thermal conductivity of ash deposits. In the first part ${ }^{12}$, we describe a novel experimental technique to measure the thermal conductivity of ash deposits in situ as they form in a pilot-scale combustor. The approach minimizes the disturbance of the natural deposit microstructure. In this second part, we employ this technique to examine the effects of densification and sintering on ash deposit thermal conductivity. SEM images are used to investigate the changes in deposit microstructure. The measured values of thermal conductivity are compared with predictions of a theoretical model.

\section{Methods}

Experiments were conducted using the Multifuel Combustor (MFC) at Sandia National Laboratories to examine the effects of sintering on the thermal conductivity of ash deposits. The experiment is designed simulate the conditions found in the convective pass of utility boilers and to minimize the disturbance of the natural deposit structure. The experimental technique is described in detail in the first part of this study 12 . In this section, we briefly describe the procedure used to sinter the deposits. We then discuss theoretical bounds for deposit thermal conductivity, and define an empirical structural parameter to measure changes in deposit microstructure.

\section{Experimental Procedure}

A $65 / 35 \%$ (by mass) blend of Illinois \#6 coal and wheat straw was fired to generate deposits. Utility-grind, pulverized coal (70\% through a 200 mesh) was prepared separately from the wheat straw. Samples of wheat straw were ground to pass through a $0.5-\mathrm{mm}$ mesh. The straw-coal 
blend formed part of a series of experiments examining the effect of cofiring on fireside combustion processes, including ash deposition 21 . Selected results from standard fuel analyses are shown in Table 1.

Table 1. Selected results from standard analysis of fuel and ash samples. The sintered deposit sample was sintered for 4 hours.

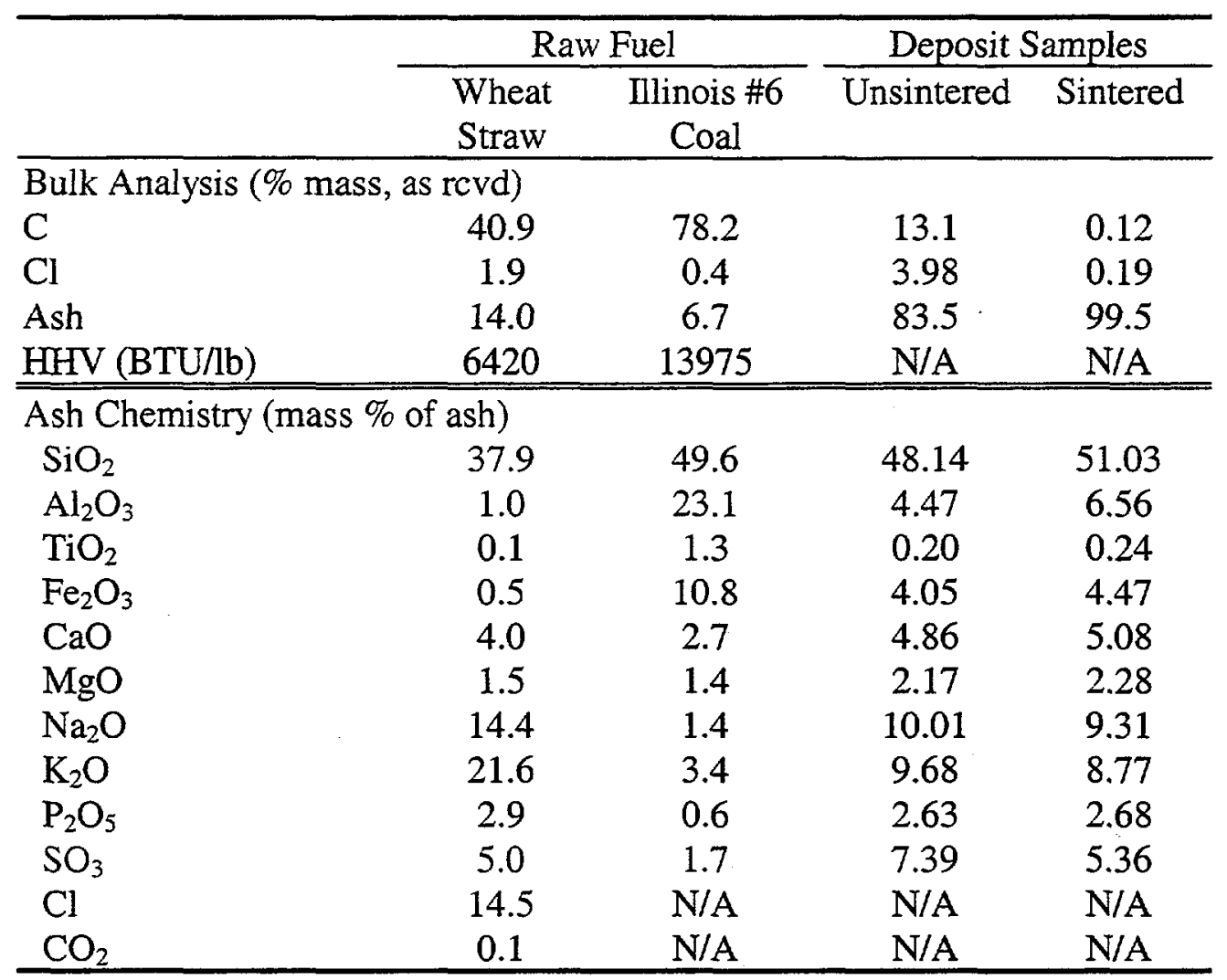

Experiments are conducted in two stages to examine the effects of sintering on deposit thermal conductivity. During the growth stage, deposits are collected at relatively low probe surface temperatures $\left(300\right.$ to $\left.450^{\circ} \mathrm{C}\right)$ to create a loose, unsintered, particulate deposit. After a sufficiently thick deposit forms, the solid fuel feed is turned off and the deposit is sintered by increasing the ambient gas (and deposit) temperature by firing the MFC natural gas burner, injecting natural gas into the lower furnace immediately above the deposit, and increasing the MFC wall temperature. We refer to this second stage of the experiment as the sintering stage.

We use the deposit solid fraction as a measure of the extent of deposit sintering. The solid fraction, $\phi$, is the ratio of the volume of the solid phase to the total volume of the deposit. We 
determine the solid fraction from the deposit mass measured at the end of an experiment, the deposit volume determined from the deposit thickness scans, and an assumed density of the deposit solid phase of $2.2 \mathrm{~g} \mathrm{~cm}^{-3}$. We assume that the mass of the deposit does not change during the sintering phase of an experiment; therefore, we can determine the time history of deposit solid fraction by monitoring the changes in deposit volume while sintering.

At the end of each experiment the deposit is removed from the probe for further analysis. A standard ash analysis provides the bulk elemental composition of the deposit. SEM analysis generates electron micrographs of deposit microstructure. Two procedures were used to prepare samples for SEM analysis. The first procedure involves impregnating deposit pieces in epoxy. The samples are then cross-sectioned, polished, and carbon coated; we refer to these samples as potted samples. The potted samples are cross-sectioned normal to the probe surface to allow examination of the radial variations in microstructure. Mounting the samples in epoxy allows for quantitative image analysis because the SEM only detects the solid and void space that intersects the cross-sectioned plane. The second procedure involves directly carbon coating deposit pieces; we refer to these samples as unpotted samples. The unpotted samples are positioned in the SEM to allow detailed examination of the inside and outside surface of the deposit.

\section{Theoretical Limits and the Structural Parameter}

Theoretical limits for the effective thermal conductivity of porous materials are useful reference points for evaluation of the measurements. We compare the measured values of deposit thermal conductivity to the simplest, lowest-order theoretical bounds ${ }^{4}$. Treating the gas and solid phases as if they independently conduct heat in parallel defines an upper limit for the effective thermal conductivity,

$$
\mathrm{k}_{\mathrm{up}}=(1-\phi) \mathrm{kg}_{\mathrm{g}}+\phi \mathrm{k}_{\mathrm{s}}
$$

where $\phi$ is the deposit solid fraction, $\mathrm{k}_{\mathrm{g}}$ is the gas phase thermal conductivity, and $\mathrm{k}_{\mathrm{s}}$ is the solid phase thermal conductivity. Treating the gas and solid phases as if they conduct heat in series defines a lower limit,

$$
\mathrm{k}_{\text {low }}=\frac{\mathrm{k}_{\mathrm{s}} \mathrm{kg}_{\mathrm{g}}}{(1-\phi) \mathrm{k}_{\mathrm{s}}+\phi \mathrm{kg}_{\mathrm{g}}}
$$


Although many higher-order (tighter) bounds have been derived for porous materials ${ }^{4}$, these bounds typically assume an isotropic structure and, therefore, cannot be applied to ash deposits, which are commonly highly anisotropic. Torquato and $\operatorname{Sen}^{22}$ discuss higher-order bounds for anisotropic materials; application of these bounds requires detailed information about the deposit microstructure.

Equations (1) and (2) are intended to provide a rational basis for comparison; they are not rigorous theoretical bounds for the thermal conductivity of ash deposits. For example, deposits with very small pore sizes (smaller than the mean free path of air) could have an effective thermal conductivity below the lower limit defined by equation (2); radiation can result in effective thermal conductivity greater than the upper limit defined by equation (1).

We need values for the thermal conductivity of the gas and solid phase material to evaluate the theoretical limits. We use a value of $0.06 \mathrm{~W} /(\mathrm{m} \mathrm{K})$ for $\mathrm{k}_{\mathrm{g}}$, which is comparable to the thermal conductivity of air at typical deposit temperatures. Assigning a thermal conductivity value to the solid phase is more difficult because the deposit chemical composition is largely unknown. Ash compositions (for example, see Table 1) are commonly reported on an oxide basis as a matter of practice; the analytical techniques do not provide any information on chemical composition. Previous work indicates that the thermal conductivity of the deposit solid phase cannot be approximated using a weighted average based on the mass proportion of the oxides $^{23}$, although it presumably could be approximated as the weighted average of the species actually present in the deposit. Because these species are not precisely known but generally are dominated by silica and aluminum silicates, we use a constant value of $3 \mathrm{~W} /(\mathrm{m} \mathrm{K})$ for $\mathrm{k}_{\mathrm{s}}$, which is representative of the thermal conductivity of silica-containing materials at high temperature 24 . Using the aforementioned values for $\mathrm{k}_{\mathrm{g}}$ and $\mathrm{k}_{\mathrm{s}}$, the upper limit is on average 9 times greater than the lower limit, with a maximum difference of a factor of 13 . The large difference between the lower and upper bounds is characteristic of porous materials such as ash deposits that consist of two phases with very different thermal conductivities and underscores the importance of structural information in determining deposit thermal conductivity.

Since the theoretical limits defined by equations (1) and (2) correspond to extremes in deposit microstructure, we use these limits define an empirical structural parameter, 


$$
\chi(\phi)=\frac{k_{\text {meas }}(\phi)_{-} k_{\text {low }}(\phi)}{k_{\text {up }}(\phi)_{-} k_{\text {low }}(\phi)},
$$

where $k_{\text {meas }}$ is the measured value of deposit thermal conductivity. This parameter provides a useful metric for the interpretation of the experimental results that reflects the microstructure of the deposit. Assuming Equations (1) and (2) define rigorous bounds, the structural parameter varies between 0 and $1(0 \leq \chi(\phi) \leq 1)$. Values close to 0 indicate a deposit with a more layered structure whereas those close to 1 indicate a deposit with a more columnar structure. This parameter is a global parameter that accounts for the effects of any non-uniformity on the net heat transfer rate through the deposit. Both the solid fraction and the structural parameter are required to uniquely define the deposit thermal conductivity.

\section{Results and Discussion}

A series of experiments were conducted while firing the $65 / 35$ blend of Illinois \#6 coal and wheat straw to examine the effects of sintering and densification on deposit thermal conductivity. In this section we first describe the measurements of deposit thermal conductivity. We then discuss the relationship between the trends in deposit thermal conductivity and the changes in deposit microstructure, deposit temperature, and deposit chemical composition. Finally, we compare the thermal conductivity measurements to predictions of a theoretical model.

\section{Measurements of Deposit Thermal Conductivity}

Figure 1 presents measurements that illustrate the effect of sintering on deposit thermal conductivity. Plotted are time-resolved measurements of the average deposit thickness (Figure 1a), the average probe and deposit surface temperatures (Figure 1b), the deposit solid fraction (Figure 1c), the deposit structural parameter (Figure 1d), and the deposit thermal conductivity (Figure 1e). The experiment was conducted in two stages, which are separated by the heavy vertical line in Figure 1. The growth stage of the experiment occurred between 0 and 2.5 hours elapsed time during which a highly porous, unsintered deposit was collected. At the end of this first stage, the solid fuel feeder was turned off and the deposit temperature was increased to induce sintering and densification. The sintering stage of the experiment lasted for approximately 12 hours. 


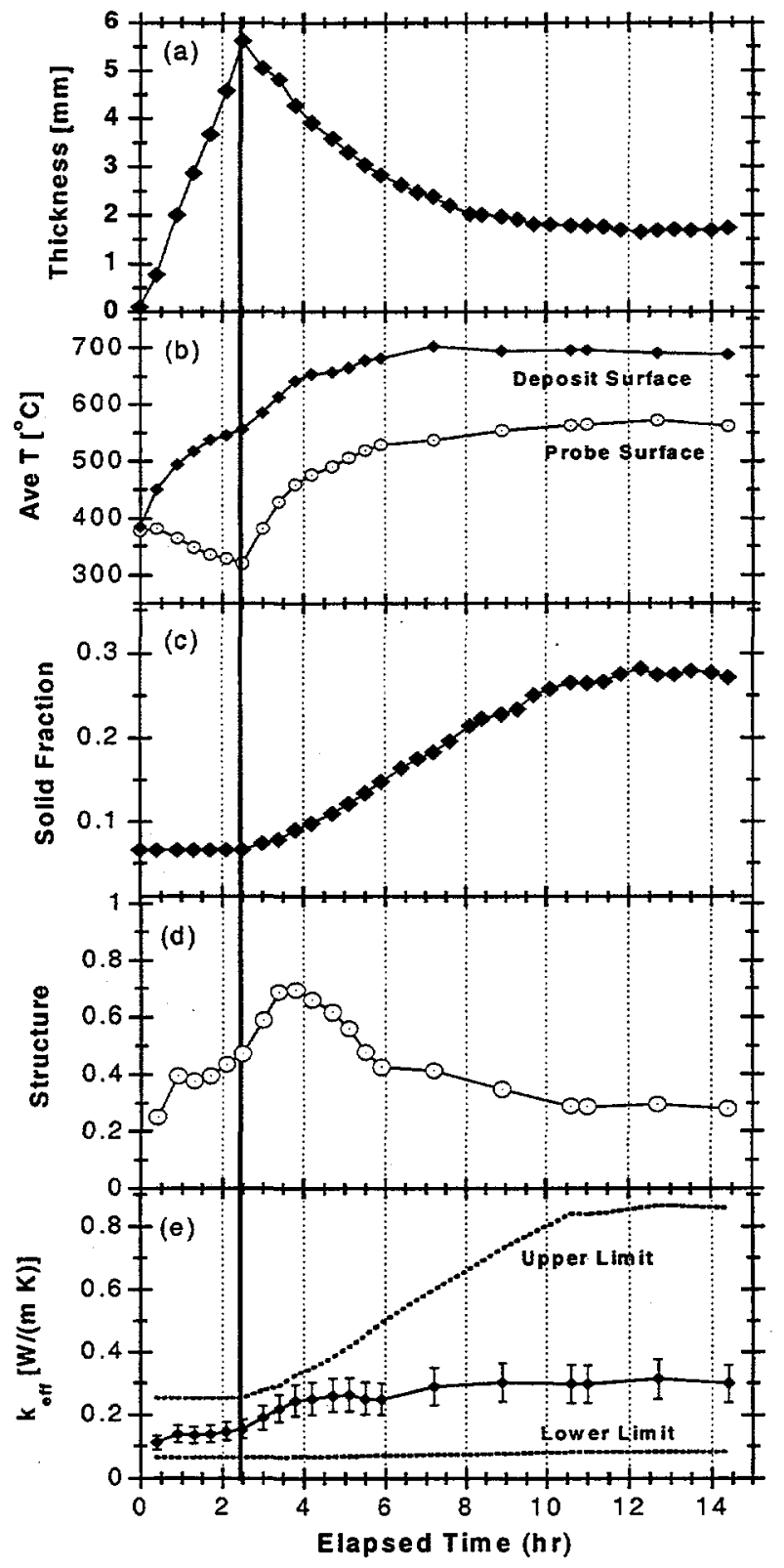

Figure 1 Measurements of (a) average deposit thickness, (b) average probe and deposit surface temperature, and (c) deposit solid fraction, (d) deposit structural parameter, and (e) deposit effective thermal conductivity as a function of time. This deposit was created while firing the blend of Ilinois \#6 and wheat straw. Figure (e) also compares the measured values to theoretical limits for deposit thermal conductivity. The thick vertical line indicates the transition between the growth and sintering phases of the experiment. Vertical bars in (e) indicate estimate of experimental uncertainty. 
The deposit formed during the growth phase of the experiment ( $0-2.5$ hours) has an average thermal conductivity of $0.14 \mathrm{~W} /(\mathrm{m} \mathrm{K})$ and a measured solid fraction of 0.07 . This very porous deposit consisted of loose, unconsolidated particles, which can easily be blown or knocked off the probe. The unconsolidated nature of the deposit is due to the low average deposit temperature of $\sim 450^{\circ} \mathrm{C}$ during the growth phase of the experiment. We expect that the thermal conductivity of such a deposit represents the lower extreme of the range of possible deposits that might form in real boilers.

During the sintering phase of the experiment (2.5 - 14.5 hours), the deposit thermal conductivity increased by a factor of 2.3 from 0.14 to $0.31 \mathrm{~W} /(\mathrm{m} \mathrm{K})$, and the average deposit temperature was increased to more than $650^{\circ} \mathrm{C}$. The degree of sintering is indicated by the deposit solid fraction; the higher the solid fraction the more sintered the deposit. Sintering increased the deposit solid fraction by a factor of 4 from 0.07 to 0.28 , creating a deposit that consisted of a well-consolidated, friable material that had to be scraped from the probe. Throughout the entire experiment the measured values of deposit thermal conductivity fall between the theoretical limits.

There are two important points to be made regarding the changes in deposit thermal conductivity observed during the sintering stage of the experiment. First, the overall trend in the measured deposit thermal conductivity more closely follows the lower theoretical limit than the upper limit. This is reflected by the falling value of the structural parameter (Figure 1d) throughout the majority of the sintering phase of the experiment, which indicates that sintering causes the measured deposit thermal conductivity to approach the lower limit. Second, the changes in deposit thermal conductivity observed during the sintering phase of the experiment occur in two distinct stages. The majority of the increase in the deposit thermal conductivity occurs between 2.5 through 4.5 hours elapsed time. During this period, the deposit solid fraction increases from 0.07 to 0.11 and the deposit thermal conductivity increases from 0.14 to 0.26 $\mathrm{W} /(\mathrm{m} \mathrm{K})-70 \%$ of the total increase in deposit thermal conductivity, but only $20 \%$ of the total increase in deposit density. Between 4.5 through $14.5 \mathrm{hr}$ elapsed time the deposit density increased by more than a factor of 2 , but the thermal conductivity only slightly increased. 
The trends in thermal conductivity shown in Figure 1 can be attributed to one or more of the several changes that occurred during the sintering phase of the experiment. Sintering significantly altered the deposit microstructure, increasing the deposit density by a factor of 4 .

The average deposit temperature rose by approximately $200^{\circ} \mathrm{C}$ during the sintering phase of the experiment. Sintering also changed the deposit chemical composition. In the next three sections, we discuss in detail the effects of these changes in order to understand the observed trends in deposit thermal conductivity.

\section{Sintering and deposit microstructure}

Ash deposit thermal conductivity is thought to depend strongly on the deposit microstructure because the thermal conductivity values of typical deposit solid phase materials are two to three order of magnitude greater than those of deposit gas phase materials. Deposit solid fraction provides the simplest measure of the changes in deposit structure that occur during sintering. Although solid fraction does not provide any structural information, it does indicate the deposit density. The deposit solid fraction (or, equivalently, porosity or deposit density) is often used as a predictor for the effects of sintering on deposit thermal conductivity 1,20 .

A plot of the measurements of deposit thermal conductivity as a function of solid fraction is shown in Figure 2. The results indicate that increases in deposit density due to sintering are not necessarily accompanied by increases in deposit thermal conductivity. Therefore, deposit solid fraction by itself is a poor predictor of the effects of sintering on deposit thermal conductivity. One must combine solid fraction with some information on the deposit microstructure to predict the changes in thermal conductivity. The trends shown in Figures 1 and 2 indicate that sintering changes the deposit microstructure in such a way to offset any potential increase in thermal conductivity due to increased deposit density.

To determine the effects of sintering on deposit microstructure, SEM analysis was performed on four deposits created under identical experimental conditions and then sintered for different periods of time $(0,1,4$, and 12 hours). Figure 3 shows time-resolved measurements of deposit thermal conductivity and solid fraction from these experiments. The changes in deposit solid fraction indicate that the deposits sintered at the same rate. The thermal conductivity measurements all exhibit the same trend - a significant increase in deposit thermal conductivity 
occurs during the initial stages of sintering; further sintering has relatively little impact on the deposit thermal conductivity.

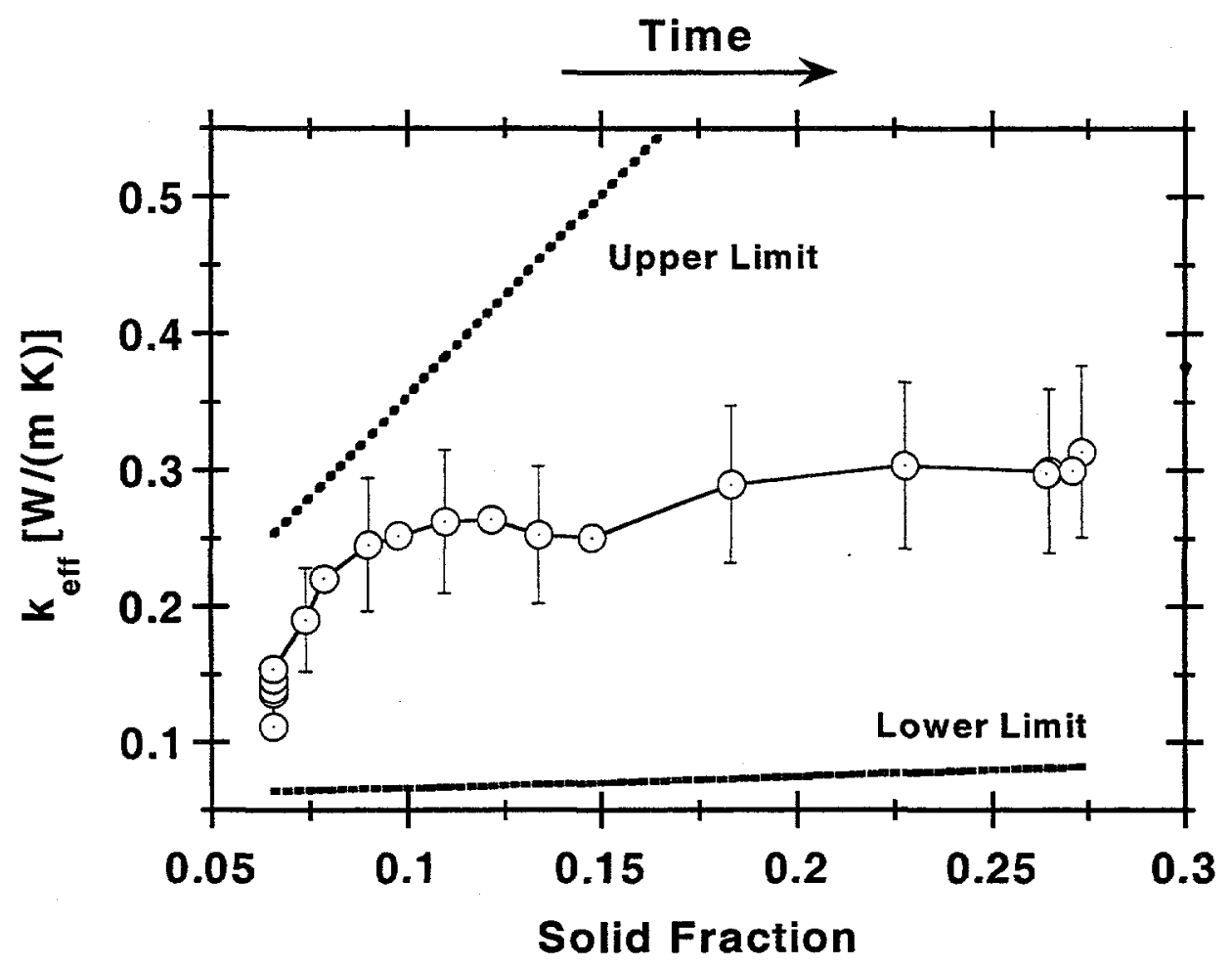

Figure 2 Thermal conductivity measurements and theoretical limits as a function of deposit solid fraction. Data are from the same experiment as those shown in Figure 1. Vertical bars show estimate of experimental uncertainty on selected data points. Time increases from left to right, but note that solid fraction does increase linearly with time as shown in Figure 1c.

Electron micrographs are shown in Figures 4 and 5 that illustrate the changes in deposit microstructure that occur during the sintering phase of the experiment. These micrographs were taken at low magnification (50X and $35 \mathrm{X}$ ) in order to assess the Iarge-scale changes in deposit structure. Figure 4 shows the cross-section of the unsintered deposit and the deposit sintered for 12 hours mounted in epoxy. Figure 5 shows the inside and outside surfaces of unpotted pieces of all four deposits. We suspect that the images over-estimate the extent of sintering on the inside surface of the deposit because the deposits are removed from the deposition probe for SEM analysis. 


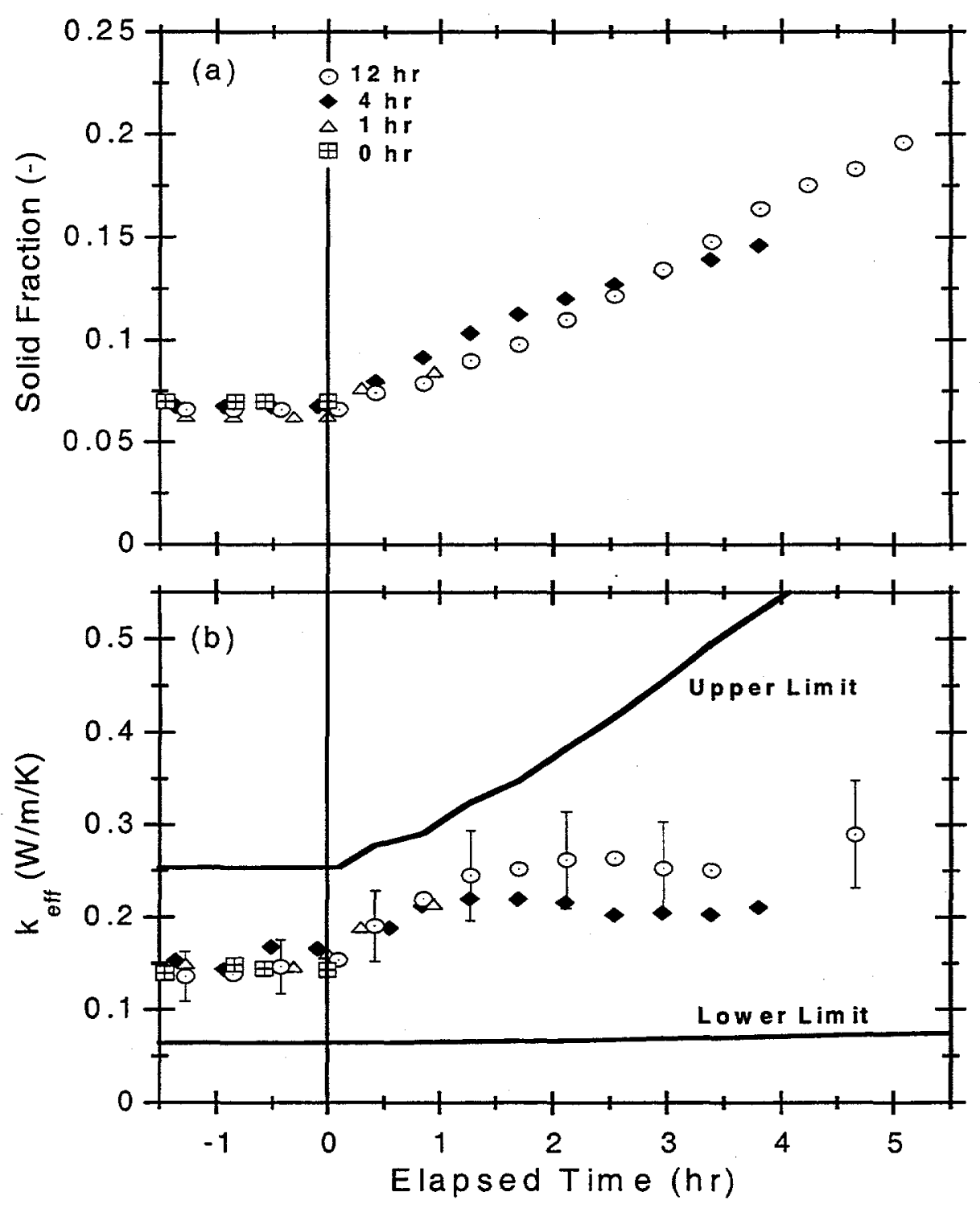

Figure 3 Measurements of (a) deposit solid fraction, and (b) deposit effective thermal conductivity as a function of time. As described in the text, these measurements were conducted under the same experimental conditions, but the experiments were terminated after different periods of sintering to examine the changes in deposit microstructure. The vertical line at 0 hours elapsed time indicates the start of sintering portion of the experiment. Data for the deposit sintered for $12 \mathrm{hrs}$ are also shown in Figures 1 and 2. The theoretical limits are calculated from the solid fraction of the deposit sintered for $12 \mathrm{hrs}$. The elapsed time for some of the thermal conductivity measurements has been slightly shifted for visual clarity. Vertical bars indicate estimate of experimental uncertainty on selected data points. 
(a) Unsintered deposit

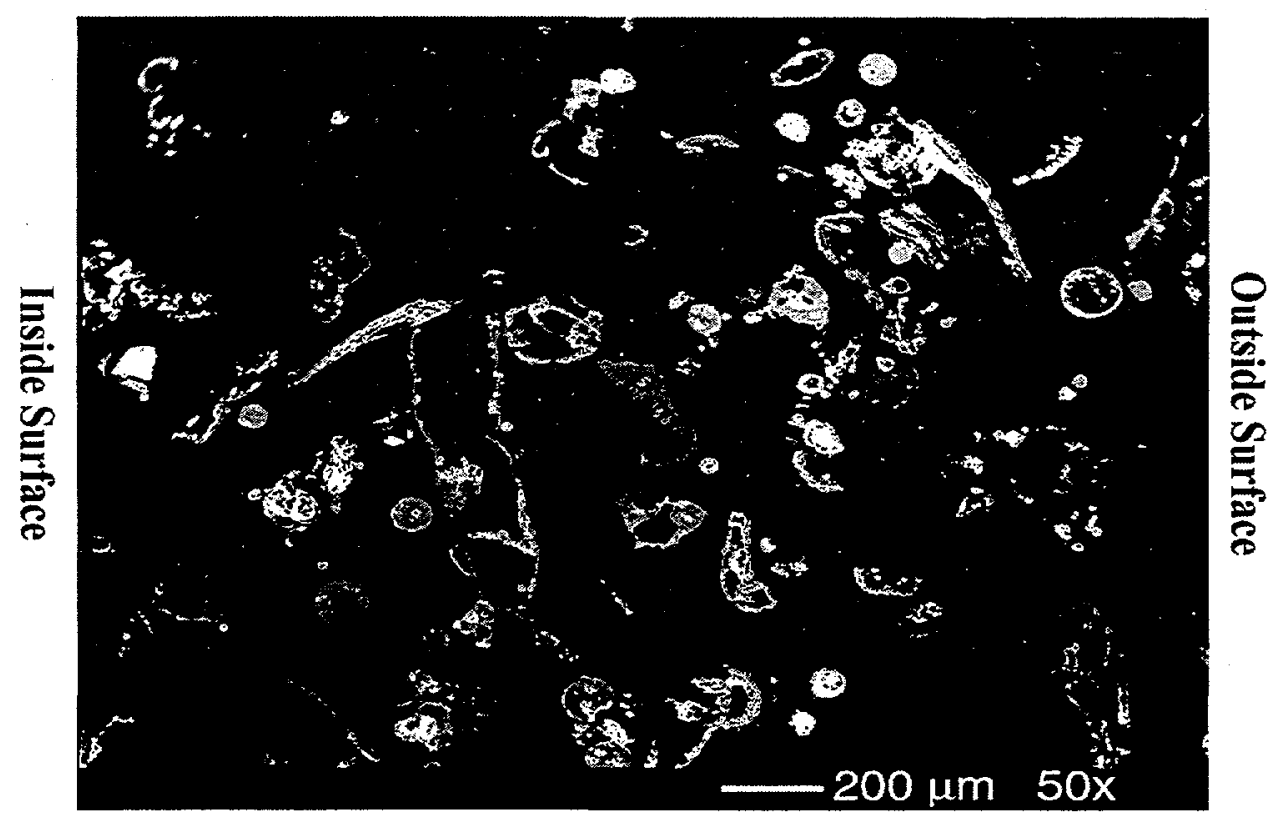

(b) Sintered deposit

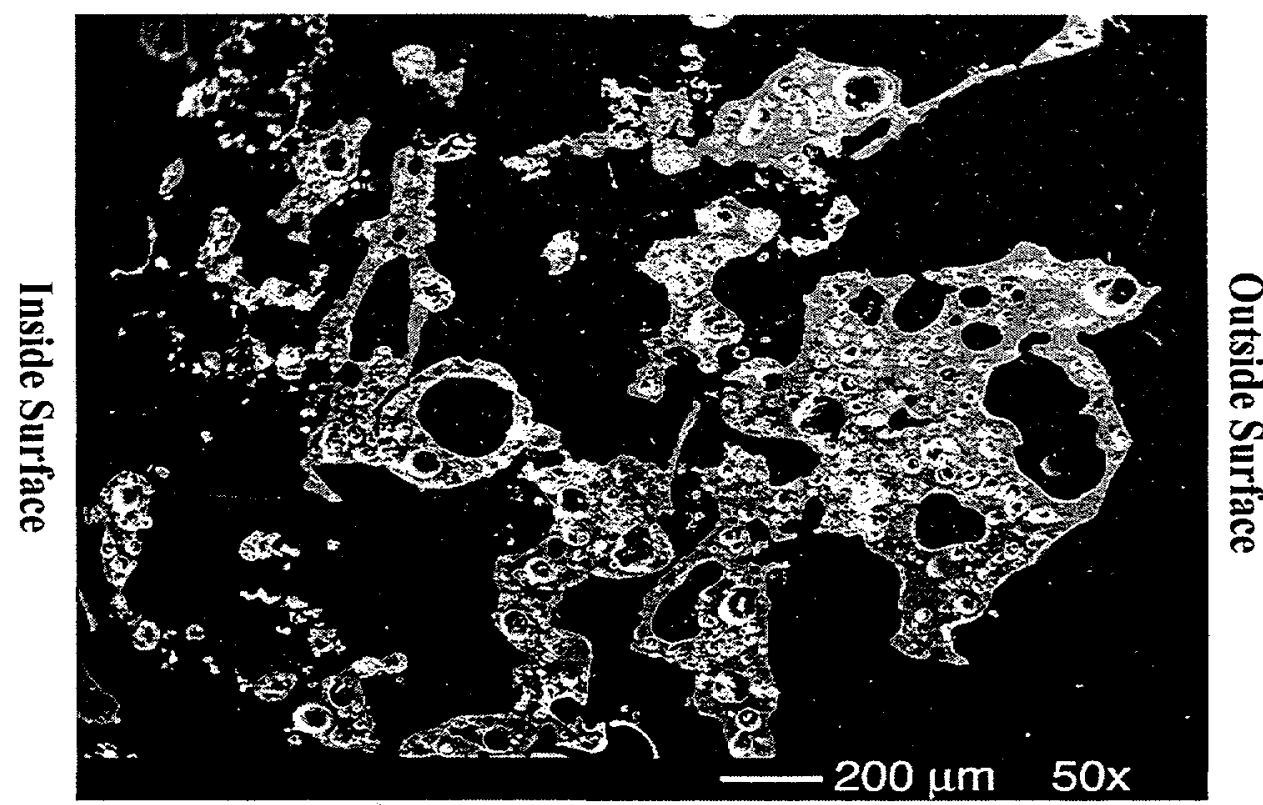

Figure 4 Electron micrographs of cross-sections of an unsintered deposit and a deposit sintered for 12 hours impregnated in epoxy. The bright regions in these images correspond to cross-sectional profiles of deposit solid phase material; the dark regions correspond to void space. The entire cross-section of the sintered deposit and part of the cross section of the unsintered deposit is shown in the figure. 


\section{INSIDE SURFACE}
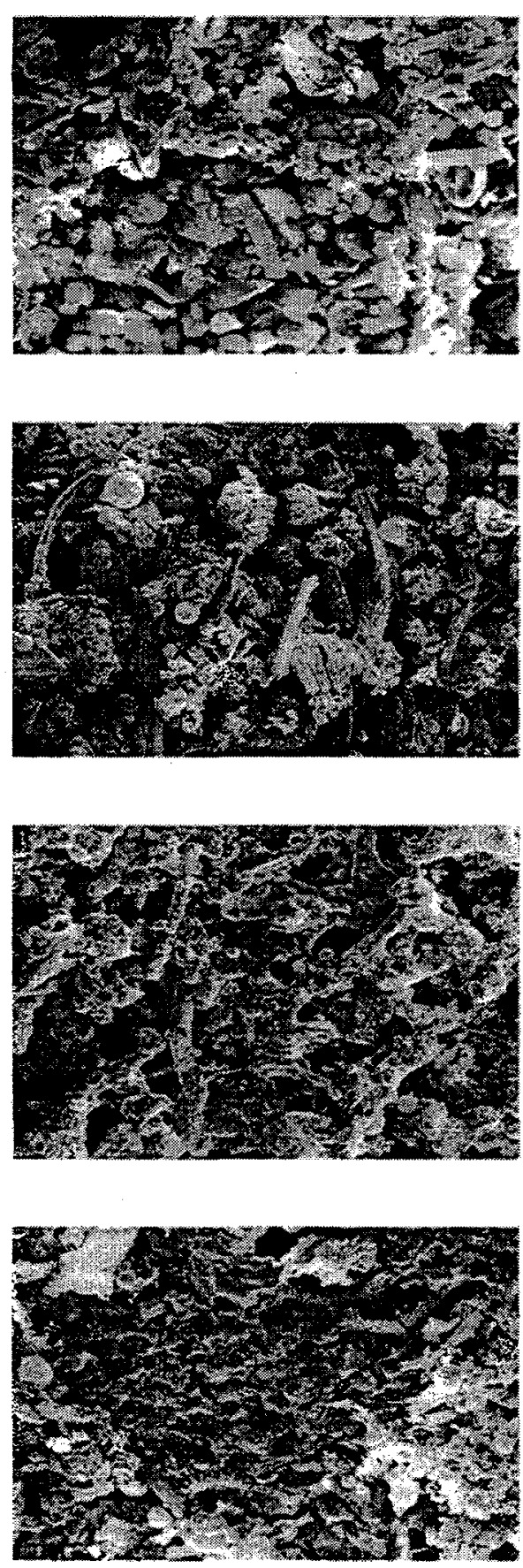

600 um $35 x$

\section{OUTSIDE SURFACE}
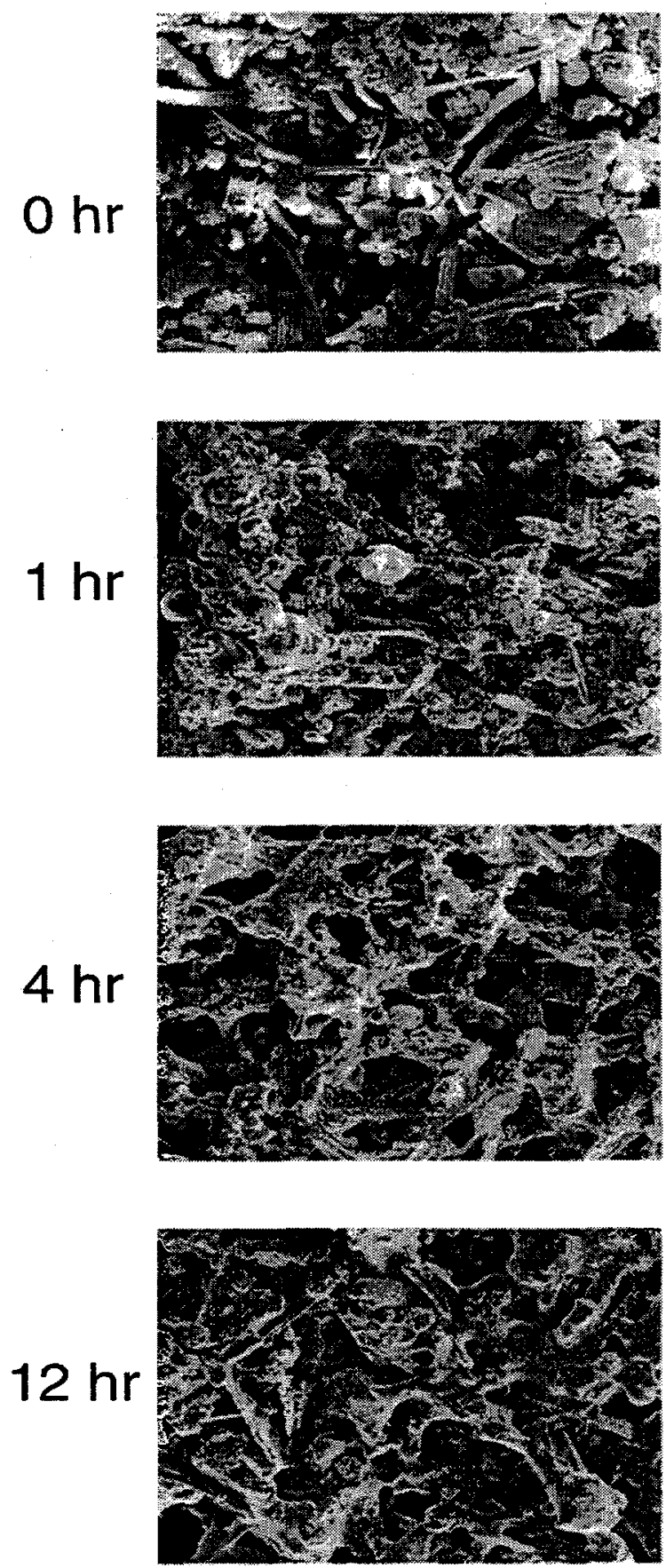

$600 \operatorname{sm} 35 x$

Figure 5 Electron micrographs of the inside and outside surface of deposits that have been sintered for $0,1,4$, and 10 hours. These deposit samples were directly carbon coated and analyzed with the SEM, as described in the text. 
Qualitative comparison of the images shown in Figure 4 reveals dramatic structural differences between an unsintered and a sintered deposit. The unsintered deposit consists primarily of distinct particles that appear isolated from their neighbors. Although the solid regions may appear isolated in the two-dimensional image, it is important to realize that the solid phase forms a continuous structure in three dimensions. The structure of the unsintered deposit appears to be isotropic - without a label one cannot tell which is the inside or outside surface of the deposit. The cross-section of a sintered deposit shows a significantly different structure instead of distinct particles, there is a substantial, interconnected solid phase. The sintered deposit clearly has an anisotropic structure with large plate-like features present near the outside surface of the deposit. The mean feature size in the sintered deposit is significantly larger than that in the unsintered deposits.

Image analysis techniques were used to quantify the differences in the microstructure of the unsintered and sintered deposits shown in Figure 4. The results of this analysis indicate that sintering creates a deposit with a layered structure. For example, using the procedures described by Ramer and Martello ${ }^{13}$ we examined the radial variations of deposit solid fraction. The solid fraction of the unsintered deposit is essentially uniform; the measured solid fraction of the inside and outside half of the unsintered deposit is 0.09 and 0.11 , respectively. In comparison, the deposit sintered for 12-hours exhibits significant radial variations in solid fraction; the measured solid fraction of the inside quarter and outside three quarters of the sintered deposit is 0.15 and 0.32 , respectively. We expect the formation of a layered deposit structure during the sintering stage of the experiment because the large temperature gradients (up to $100{ }^{\circ} \mathrm{C} / \mathrm{mm}$ ) result in a wide range of sintering rates across a deposit. The solid fraction values determined with the image analysis technique when applied to the entire deposit compare favorably to those determined form the measurements of deposit mass and deposit volume.

The electron micrographs of the unpotted deposit samples shown in Figure 5 provide additional evidence that a layered deposit structure forms during the sintering stage of the experiment. One cannot differentiate between the inside and outside surface of the unsintered deposit, which suggests a uniform deposit structure. Evidence of a layered structure can clearly be seen after only 1 hour of sintering. After 1 hour the inside surface of the deposit appears unchanged while numerous bridges have formed between particles found on the outside surface of the deposit. After 4 hours of sintering substantial bridges have formed between all of the 
particles on the outside surface, while the inside surface has a rough, porous appearance. After 4 hours of sintering there is some evidence of sintering at the inside deposit surface. After 12 hours of sintering the outside deposit surface has a smooth, interconnected structure while the inside surface still has a rough, angular structure. All of these images reveal the complex, threedimensional structure of ash deposits.

The trends in the structural parameter shown in Figure 1d also indicate that a layered deposit structure forms during the sintering phase of the experiment. During the initial stages of sintering the structural parameter increases indicating that the measured thermal conductivity is trending towards the upper limit. This suggests that that the sintering initially creates a deposit with a more columnar structure. Subsequent sintering causes the structural parameter to decreases indicating that the measured thermal conductivity is trending towards the lower limit. The physical interpretation of this trend is that sintering creates in a more layered deposit structure. The time history of the structural parameter indicates that layering occurs throughout most of the sintering phase of the experiment.

The changes in the deposit microstructure apparent in Figures 4 and 5 provide a compelling explanation for the trends in deposit thermal conductivity. The hypothesis is that the structure of the solid phase largely determines the thermal conductivity of a deposit. During the initial stages of sintering, the contact area between particles rapidly increases as point contacts between particles fuse together resulting in increased deposit thermal conductivity. This occurs primarily in the hotter outer layers of the deposit and causes the sharp increase in thermal conductivity observed during the initial stages of sintering. At later times, a relatively unsintered inner layer next to the cool probe surface dominates the overall deposit thermal conductivity. During this period, the contact area between particles no longer limits the conduction through the solid phase and the overall deposit thermal conductivity is limited by layered deposit structure that requires significant sintering to substantially alter.

\section{Sintering and Deposit Temperature}

The average deposit temperature rose by $\sim 200{ }^{\circ} \mathrm{C}$ during the sintering phase of the experiment. It is important to determine if this temperature rise is responsible for some or all of observed increase in deposit thermal conductivity independent of the changes in structure. At high temperatures, radiation can increase significantly the heat transfer rate through the deposit, 
which, in turn, increases the effective deposit thermal conductivity. The thermal conductivity of gas and some solid phase materials also increase with temperature.

Measurements of deposit thermal conductivity made at the end of the experiment as the deposit cooled down suggest that the increase in deposit temperature during the sintering phase of the experiment had relatively little direct effect on the deposit thermal conductivity. For example, reducing the average deposit temperature from $600^{\circ} \mathrm{C}$ to $450^{\circ} \mathrm{C}$ reduced the effective thermal conductivity of the deposit by less than $10 \%$ from 0.31 to $0.29 \mathrm{~W} /(\mathrm{m} \mathrm{K})$. Of course, the increase in temperature during the sintering phase of the experiment plays a critical, but indirect role, on the changes in thermal conductivity because high temperatures are required to drive the sintering and chemical reactions that cause changes in deposit structure.

\section{Sintering and deposit composition}

We performed standard elemental analysis on bulk deposit samples to evaluate the changes in chemical composition that occurred during the sintering phase of the experiment. As previously discussed, changes in deposit chemical composition can effect the thermal conductivity of the solid phase material. The bulk elemental composition of an unsintered deposit and a deposit sintered for 4 hours are shown in Table 1. The data suggest that carbon and chlorine containing species decompose during the sintering phase of the experiment. The decomposition of these species is consistent with thermodynamic equilibrium calculations; for example, at high temperatures, $\mathrm{CaO}$ is thermodynamically favored relative to $\mathrm{CaCO}_{3}$. The decomposition of the deposit carbon and chlorine species is likely to have little affect on the overall thermal conductivity of the deposit solid phase. First, carbon and chlorine make up only $17 \%$ of the deposit solid phase; therefore, loss of this material will likely have little effect on the solid phase thermal conductivity and the deposit solid fraction. Second, decomposition will likely create species with very similar values of thermal conductivity to the original species.

\section{Implications for Model Development}

Models for deposit thermal conductivity are needed to simulate the effects of ash deposition on utility boiler performance. At present, the most sophisticated models for deposit thermal conductivity account for changes in deposit density; they do not account for changes in deposit microstructure 20 . The measurements presented here indicate that models must account for changes in microstructure. The fact that sintering creates a layered microstructure suggests a 
simple conceptual framework for predicting the effects of sintering on deposit thermal conductivity. In its simplest formulation a deposit can be treated as a material with two layers and an overall thermal conductivity of

$$
\mathrm{k}=\frac{1}{\frac{\mathrm{L}}{\mathrm{k}_{\mathrm{un}}}+\frac{(1-\mathrm{L})}{\mathrm{k}_{\mathrm{si}}}},
$$

where $L$ is the thickness of the unsintered layer normalized by the total deposit thickness, $k_{\text {un }}$ is the thermal conductivity of the unsintered, inner layer of the deposit, and $\mathrm{k}_{\mathrm{si}}$ is the thermal conductivity sintered, outer layer of the deposit. Equation (4) can easily be generalized to account for a deposit with more layers; however, as will be shown, the two-layer formulation predicts the effects of sintering on deposit thermal conductivity observed in these experiments.

Calculations of the overall deposit thermal conductivity using equation (4) are shown in Figure 6. Curves are presented as a function of $k_{\mathrm{si}}$ for three different values of $\mathrm{L}$. A constant value of $0.15 \mathrm{~W} /(\mathrm{m} \mathrm{K})$ is used for $\mathrm{k}_{\mathrm{un}}$, this value corresponds to the measured deposit thermal conductivity at the beginning of the sintering phase of the experiment. The value of $k_{\mathrm{si}}$ varies between $\mathrm{k}_{\mathrm{un}}$ and $3 \mathrm{~W} /(\mathrm{m} \mathrm{K})$, the thermal conductivity of the deposit solid phase material. The calculations shown in Figure 6 describe the following conceptual scenario for the effects of sintering on deposit thermal conductivity. The initial deposit has a uniform $\left(k_{s i}=k_{u n}\right)$ thermal conductivity of $0.15 \mathrm{~W} /(\mathrm{m} \mathrm{K})$, which corresponds to the minimum value shown in Figure 6 . Sintering then occurs in the hotter outer regions of the deposit, which causes $\mathrm{k}_{\mathrm{si}}$ (the thermal conductivity of the outer layer of the deposit) to increase while $\mathrm{k}_{\mathrm{un}}$ (the thermal conductivity of unsintered, inner layer) remains constant. The more sintered the deposit the higher the value of $\mathrm{k}_{\mathrm{si}}$ implying that time increases from left to right in Figure 6.

Figure 6 indicates that the two-layer model qualitatively predicts the trends in the measured deposit thermal conductivity shown in Figure 1e. The initial stage of sintering, corresponding to the change in $\mathrm{k}_{\mathrm{si}}$ from 0.15 to $1 \mathrm{~W} /(\mathrm{m} \mathrm{K})$, causes a substantial increase in the overall deposit thermal conductivity. Subsequent sintering, corresponding to values of $k_{s i}$ greater than $1 \mathrm{~W} /(\mathrm{m}$ $\mathrm{K}$ ), has relatively little effect on the overall deposit thermal conductivity. The fact that increases in $\mathrm{k}_{\mathrm{si}}$ beyond $1 \mathrm{~W} /(\mathrm{m} \mathrm{K})$ have little impact on the overall deposit thermal conductivity indicates that after the initial sintering stage, the only way to increase the overall deposit thermal conductivity is to increase $k_{\mathrm{un}}$, the thermal conductivity of the unsintered layer. 


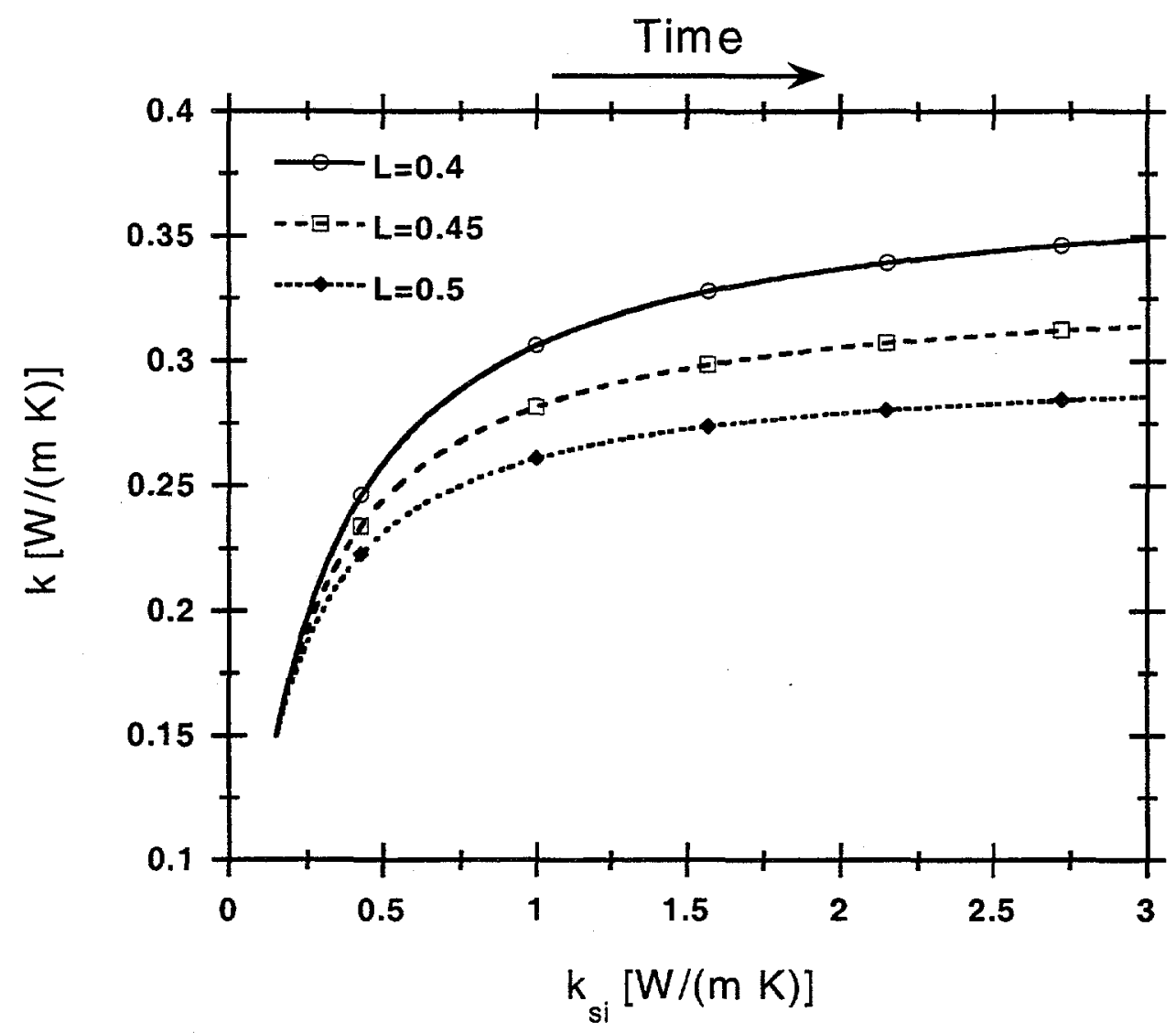

Figure 6 Calculations of the overall deposit thermal conductivity with the two-layered structure model as a function of the thermal conductivity of the sintered layer, $\mathrm{k}_{\mathrm{si}}$. Curves are shown for three different values of the nondimensional thickness of the unsintered layer, $\mathrm{L}$, and a constant value of the unsintered layer, $\mathrm{k}_{\mathrm{un}}$.

Sensitivity analysis indicates that if the unsintered layer is more than $20 \%$ of the deposit thickness, it largely determines the overall deposit thermal conductivity.

In order to compare predictions of the two-layered model to the measurements of deposit thermal conductivity we need estimates for $k_{\mathrm{un}}, \mathrm{k}_{\mathrm{si}}$, and $\mathrm{L}$ from an actual deposit. Sensitivity analysis reveals that the critical parameter is $k_{u n}$ if $L$ is greater than 0.2 and the ratio of $k_{\text {si }}$ to $k_{u n}$ is greater than about 3 . We use a constant value of $0.15 \mathrm{~W} /(\mathrm{m} \mathrm{K})$ for $k_{u n}$, which is the measured deposit thermal conductivity at the beginning of the sintering phase of the experiment. We assume a constant value of 0.4 for $\mathrm{L}$. Finally, we assume that $\mathrm{k}_{\mathrm{si}}$ varies linearly with the solid fraction of the sintered layer. The slope and intercept of this relationship is defined by the measured solid fraction and thermal conductivity of the deposit at the start of the sintering phase 
of the experiment and of the solid phase material. The time history of the sintered layer solid fraction is determined from the measurements of the overall deposit solid fraction (Figure 1c), L, and assuming the solid fraction of the unsintered layer remains constant. The predictions of the overall deposit thermal conductivity are relatively insensitive to the assumed functional form of $\mathrm{k}_{\mathrm{si}}$.

Figure 7 compares predictions of the two-layered model to the measurements of deposit thermal conductivity shown in Figure 1e. The accuracy of the predictions provides additional evidence for the importance of a layered deposit structure in determining the effects of sintering on deposit thermal conductivity. The results shown in Figure 7 also underscore the dominant role that an unsintered layer with a low value of thermal conductivity can have on the overall deposit thermal conductivity. After 4 hours of sintering, the overall deposit thermal conductivity is limited by $k_{u n}$. The effect of a low thermal conductivity unsintered layer explains why only small changes in deposit thermal conductivity were observed in our experiments after substantial sintering.

\section{Conclusions}

This paper describes experiments conducted to examine the effects of sintering and changes in microstructure on ash deposit thermal conductivity. The experiments were performed on deposits formed while firing a blend of Illinois \#6 coal and wheat straw. The measurements were made in situ while the deposits formed and then sintered in a pilot-scale combustor. The deposits are representative of those found in the convective pass of a utility boiler. Initial stages of sintering are characterized by a substantial increase in deposit thermal conductivity; subsequent sintering has little effect on deposit thermal conductivity. Analysis of SEM images of deposit samples indicates that sintering creates a layered microstructure. Sintering significantly changes the microstructure of the outer layers, but has relatively little effect on the innermost layer of the deposit located adjacent to the cool deposition probe. Theoretical analysis that treats the deposit as a two layered material predicts the observed trends in deposit thermal conductivity. The model indicates that a low thermal conductivity layer largely determines the overall thermal conductivity of the deposit. Therefore, after the initial stages of deposit sintering, the thermal conductivity of the innermost, unsintered layer must be increased to increase the overall thermal conductivity of the deposit. 


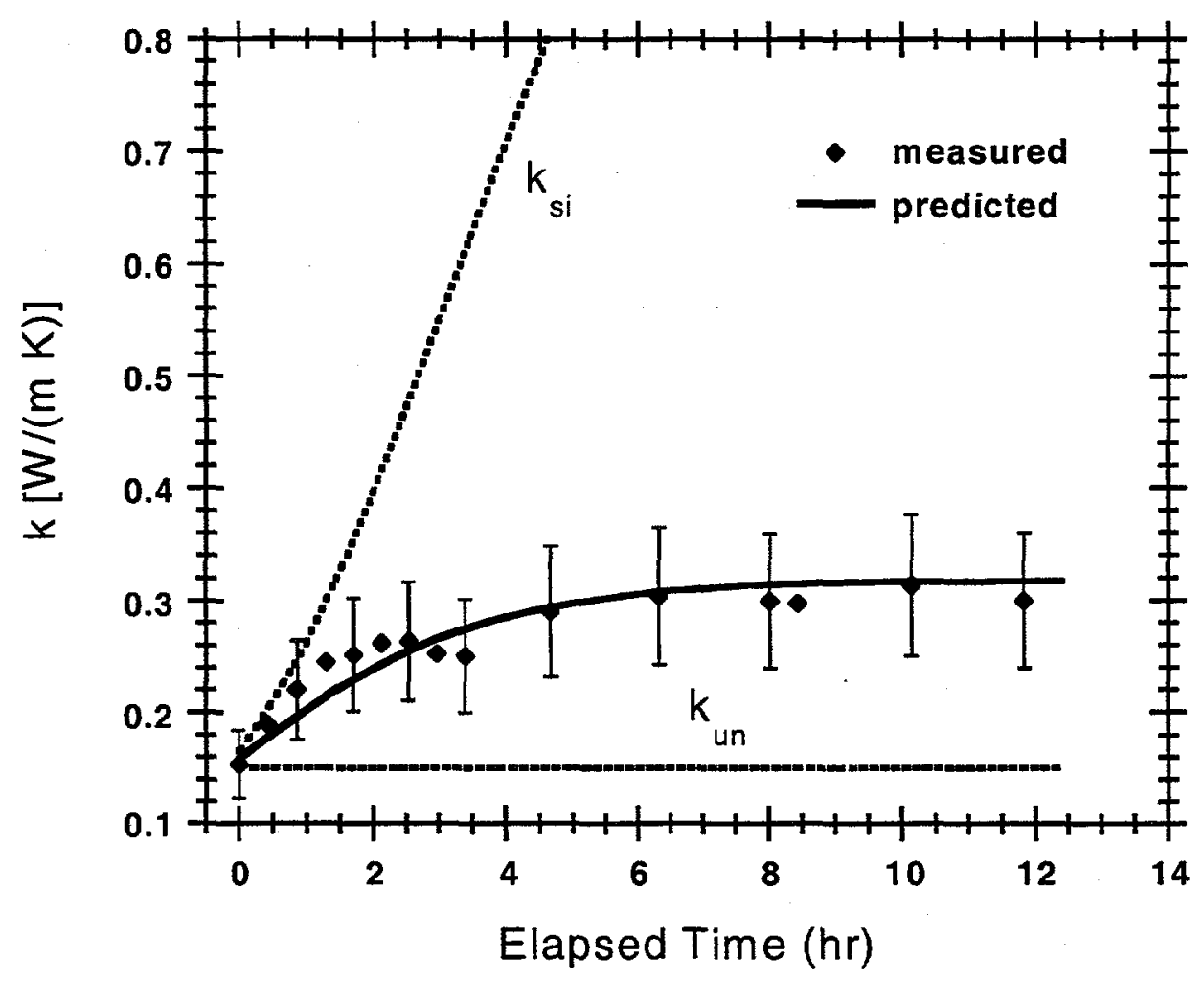

Figure 7 Comparison of the measurements of deposit thermal conductivity shown in Figure $1 \mathrm{e}$ to predictions of the two-layered structure model as a function of time. The values of $\mathrm{k}_{\mathrm{un}}, \mathrm{k}_{\mathrm{si}}$, and $\mathrm{L}$ used to evaluate the model are described in the text. Elapsed time corresponds to the sintering stage of the experiment. Vertical bars indicate estimate of experimental uncertainty on selected data points.

This study represents a significant advance in our ability to examine the impact of sintering on deposit thermal conductivity. By making in situ measurements that minimally disturb the natural deposit microstructure, we were able for the first time to examine the effects of sintering on deposit microstructure and deposit thermal conductivity. Although it is generally recognized that sintering creates layered deposits, these measurements are the first, to our knowledge, that quantifies the effects of layering on real deposits. Anderson et al. ${ }^{7}$ present data which show that sintering increases the thermal conductivity of the outer layers of a deposit. However, their data do not reveal the significant effect of the unsintered inner layer on the overall deposit thermal conductivity. This is likely due to the fact that their measurements were made using crushed 
deposit material, which probably do not have the same structure as actual deposits. In addition, the temperature of the inside surface of the deposit exceeded $750^{\circ} \mathrm{C}$, which is much higher than typical superheater tube temperatures in actual boilers. This high temperature likely caused substantial sintering of the innermost deposit layer.

The results demonstrate that, for the ash deposits considered here, thermal conductivity depends strongly on deposit microstructure. The deposit solid fraction (or, equivalently, porosity or deposit density) cannot be used by itself as a measure of the effects of sintering on deposit thermal conductivity. This has implications on the development of models for deposit thermal conductivity. Models must account for effects of changes in microstructure on deposit thermal conductivity; current models do not account for these effects. The most sophisticated models use deposit porosity or solid fraction as the measure of the effects of sintering 20 . For the deposits examined in this study, this is not a valid approach. The success of the simple two-layered model in predicting the observed changes in deposit thermal conductivity suggest that such a model may be a useful approach for accounting for the effects of changes in deposit microstructure on deposit thermal conductivity. Predictions of this model critically depend on the thermal conductivity of an unsintered layer; even a very thin layer with a low thermal conductivity can significantly limit the overall thermal conductivity of a deposit.

\section{Acknowledgements}

This work was sponsored by the U.S. DOE FETC, Advanced Research and Technology Development Coal Utilization Program. A.L. Robinson was also supported in part by an appointment to the U.S. Department of Energy Fossil Energy Research Participation Program at the Federal Energy Technology Center in Pittsburgh, Pennsylvania, administer by the Oak Ridge Institute for Science and Education.

\section{References}

(1) Wall, T. F.; Bhattacharya, S. P.; Zhang, D. K.; Gupta, R. P.; He, X. Progress in Energy and Combustion Science 1993, 19, 487-504.

(2) Gupta, R. P.; Wall, T. F.; Baxter, L. L. The thermal conductivity of ash deposits: Particulate and slag structures; Gupta, R. P.; Wall, T. F.; Baxter, L. L., Ed.; Engineering Foundation: Kona HI, 1997. 
(3) Kaviany, M. Principles of heat transfer in porous media; Springer-Verlag: New York, 1991.

(4) Torquato, S. Applied Mechanics Review 1991, 44, 37-76.

(5) Baxter, L. L. Fuel Processing Technology 1998, 56, 81-88.

(6) Baxter, L. L. Biomass and Bioenergy 1993, 4, 85-102.

(7) Anderson, D. W.; Viskanta, R.; Incropera, F. P. Transactions of the ASME Journal of Engineering for Gas Turbines and Power 1987, 109, 215-221.

(8) Boow, J.; Goard, P. R. C. Journal of the Institute of Fuel 1969, 42, 412-419.

(9) Mulcahy, M. F. R.; Boow, J.; Goard, P. R. C. Journal of the Institute of Fuel 1966, 39, 385-394.

(10) Mills, K. C.; Rhine, J. M. Fuel 1989, 68, 904-910.

(11) Belov, S. Y.; Vasil'ev, V. V.; Kovalevich, I. A.; Teterina, T. M. Teploenergetika (Thermal Engineering) 1993, 40, 692- 694.

(12) Robinson, A. L.; Buckley, S. G.; Baxter, L. L. Submitted to Energy \& Fuels 2000.

(13) Ramer, E. R.; Martello, D. V. Characterization of ash deposit structure from planar sections: Results and challenges; Ramer, E. R.; Martello, D. V., Ed.; Plenum Press: New York, 1996, pp 309-323.

(14) Wang, H.; West, H.; Harb, J. N. Energy \& Fuels 1999, 13, 570-578.

(15) Bouris, D.; Bergeles, G. International Joumal of Heat and Mass Transfer 1997, 40, 4073-4084.

(16) Wang, H.; Harb, J. N. Progress in Energy and Combustion Science 1997, 23, 267-282.

(17) Lee, F. C. C.; Lockwood, F. C. Progress in Energy and Combustion Science 1999, 25, 117-132.

(18) Senior, C. L. Energy \& Fuels 1997, 11, 416-420.

(19) Allan, S. E.; Erickson, T. A.; McCollor, D. P. Modeling of ash deposition in the convective pass of a coal-fired boiler; Allan, S. E.; Erickson, T. A.; McCollor, D. P., Ed.; Plenum Press: New York, 1996, pp 451-470.

(20) Richards, G. H.; Slater, P. N.; Harb, J. N. Energy \& Fuels 1993, 7, 774-781.

(21) Robinson, A. L.; Junker, H.; Buckley, S. G.; Sclippa, G.; Baxter, L. L. Interactions between Coal and Biomass when Cofiring; Robinson, A. L.; Junker, H.; Buckley, S. G.; Sclippa, G.; Baxter, L. L., Ed.; Combustion Institute: Boulder, CO, 1998, pp 1351-1359. 
(22) Torquato, S.; Sen, A. K. Journal of Applied Physics 1990, 67, 1145-1155.

(23) Wall, T. F.; Bhattacharya, S. P.; Zhang, D. K.; Gupta, R. P.; He, X. The properties and thermal effects of ash deposits in coal-fired furnaces: A review; Wall, T. F.; Bhattacharya, S. P.; Zhang, D. K.; Gupta, R. P.; He, X., Ed.; Taylor \& Francis: Washington D.C., 1994, pp 463-477.

(24) Touloukian, Y. S. Thermophysical properties of high termperature solid materials; MacMillan Co: NY, 1967. 


\section{DISTRIBUTION:}

Dr. Donald Aitken

Union of Concerned Scientists

2625 Alcatraz Ave., Suite 505

Berkeley, CA 94705

Dr. Suresh P. Babu

Institute of Gas Technology

1700 South Mount Prospect Road

DES PLAINES, Illinois 60018-1804

Mr. Phillip Badger

Tennessee Valley Authority

SE Regional Biomass Program

PO Box 1010

Muscle Shoals, AL 35662-1010

Dr. Richard Bain, Manager

Biomass Power Program

National Renewable Energy Laboratory

1617 Cole Boulevard

Golden, Colorado 80401-3393

Dr. Steve Benson

UND Energy and Environ. Res. Center

P.O. Box 9018

Grand Forks, ND 58202-9018

Mr. William M. Burnett

Senior Vice President

Technology Development

Gas Research Institute

8600 West Bryn Mawr Avenue

Chicago, IL 60631

Mr. William H. Carlson

Wheelabrator Environmental Systems

20811 Industry Road

Anderson, CA 96007

Mr. Kevin Craig

Biomass Power Program

National Renewable Energy Laboratory

1617 Cole Boulevard

Golden, Colorado 80401-3393
Dr. Raymond Costello

Manager

Biomass Power Program, EE-13

U.S. DOE

1000 Independence Avenue, SW

Washington, D.C. 20585

Dr. Stefan Czernik

Research Chemist

National Renewable Energy Laboratory

1617 Cole Boulevard

Golden, Colorado 80401-3393

Professor John W. Daily

Univ. of Colorado at Boulder

Mechanical Engineering Dept.

Boulder, CO 80309-0427

Dr. Kevin Davis

Reaction Engineering International

77 West 200 South, Suite 210

Salt Lake City, UT 84101

Dr. David Dayton

Staff Thermochemical Scientist

National Renewable Energy Laboratory

1617 Cole Boulevard

Golden, Colorado 80401-3393

Dr. Thomas H. Dunning, Jr., Manager

Molecular Sciences Research Center

Pacific Northwest National Laboratories

P. O. Box 999, MS K2-20

Richland, WA 99352

Prof. Christopher F. Edwards

Dept. of Mechanical Engineering

Stanford University

Stanford, CA 94305-3032

Dr. Robert Evans

National Renewable Energy Laboratory

1617 Cole Boulevard

Golden, Colorado 80401-3393 
DISTRIBUTION: (continued)

Dr. Robert B. Finkelman

U.S. Geological Survey

956 National Center

Reston, VA 22092.000

Prof. Rick Flagan

California Institute of Technology

Environmental Engineering Dept.

Mailcode 138-78

Pasadena, CA 91125

Prof. Thomas Fletcher

Department of Chemical Engineering 350

Clyde Building

Brigham Young University

Provo, UT 84602

Dr. Patrick F. Flynn

Vice President, Research \& Technology

Cummins Engine Company

Mail Code 50181, Box 3005

Columbus, IN 47202-3005

Dr. W. James Frederick Jr.

Institute of Paper Science And Technology

500 - 10th Street NW

Atlanta, GA 30318

Ms. Alia Ghandour

Director of International Programs

National BioEnergy Industries

Association (NBIA)

1212 C St. NW, 4th Floor

Washington, DC 20001-2109

Mr. Philip Goldberg

US DOE / NETL

922-342

626 Cochran Mill Road

P.O. Box 10940

Pittsburgh, PA 15236-0940
Dr. J. Peter Gorog

Research and Development

Pulp, Paper and Packaging

Weyerhaeuser Company

WTC $2 \mathrm{H} 22$

Tacoma, WA 98477

Mr. Jeff Graef

W Regional Biomass Energy Program

Nebraska Energy Office

$1200 \mathrm{~N}$ Street Suite 110

Lincoln, NE 68509-5085

Mr. Richard Handley

NE Regional Biomass Energy Program

Coneg Policy Research Center Inc.

400 N Capital St NW Suite 382

Washington, DC 20001

Professor Ronald K. Hanson, Chair

Department of Mechanical Engineering

Stanford University

Stanford, CA 94305

Dr. Mike Heap

Reaction Engineering International

77 West 200 South_Suite 210

Salt Lake City, UT 84101

Dr. Evan Hughes

Manager, Renewable Fuels

Electric Power Research Institute

3412 Hillview Avenue

P.O. Box 10412

Palo Alto, CA 94303

Prof. Robert Hurt

Division of Engineering

Brown University

Box D

Providence, RI 02912 
DISTRIBUTION: (continued)

Dr. Ari Huttunen

EPRI

Coal Combustion \& Renewables

Energy Conversion

3412 Hillview Ave.

Palo Alto, CA 94304-1395

Professor Bryan M Jenkins

University of California, Davis

Biological and Ag. Eng. Dpt.

Davis, CA 95616-5294

Dr. Andrew K. Jones

International Paper

Manufacturing Technology Center

6285 Tri-Ridge Blvd.

Loveland, OH 45140-7910

Mr. Frederick Kuzel

Council Great Lakes Governors

Great Lakes Regional Biomass Program

35 E Wacker Drive Suite 1850

Chicago, IL 60601

Dr. Steve Londerville

Director of Research \& Development

The Coen Company, Inc.

1510 Rollins Road

Burlingame, CA 94010

Professor Gregory J. McRae

Department of Chemical Engineering

Massachusetts Institute of Technology

Room 66-372

77 Massachusetts Avenue

Cambridge, MA 02139-4307

Dr. Arun Mehta

Electric Power Research Institute

3412 Hillview Avenue

Palo Alto, CA 94304-1395
Mr. Thomas R. Miles

Consulting Design Engineer

5475 SW Arrowwood Lane

Portland, OR 97225

Professor Reginald E. Mitchell

Dept. of Mechanical Engineering

Stanford University

HTGL 520C,

Stanford, CA 94305-3032

Dr. Gregory P. Morris

Future Resources Associates, Inc.

2039 Shatuck Ave. Suite 402

Berkeley, CA 94704

Dr. Ralph P. Overend

National Renewable Energy Lab

1617 Cole Boulevard

Golden, CO 80401-3393

Mr. Pekka Pakkala

Embassy of Finland

Technology Center

3301 Massachusetts Ave., NW

Washington, DC 20008

Prof. David Pershing

University of Utah

2202 MEB

Salt Lake City, UT 84112

Dr. Thomas Reed

Colorado School of Mines

1810 Smith Road

Golden, CO 80401

Ms. Valri Robinson

Office of Industrial Technologies

DOE, EE-22, Room 5F-035

Washington D.C. 20585 
DISTRIBUTION: (continued)

Mr. Robert Roscoe

Weyerhaeuser

Technology Center

Federal Way, WA 98003

Prof. Daniel E. Rosner

Yale University

Mason Laboratory

New Haven, CT 6520

Prof. Adel Sarofim

Univ. of Utah \& MIT

Dept. of Chemical Eng.

Salt Lake City, UT 84112

Dr. Daniel J. Seery

Senior Program Manager

Environmental Science

United Technologies Research Center

East Hartford, CT 06108

Dr. David G. Sloan

ABB-Combustion Engineering, Inc.

2000 Day Hill Road

Windsor, CT 6095

Prof. Philip Smith

Dept. of Chemical and Fuels Engineering

2250 Merrill Engineering Building

Salt Lake City, UT 84112

Prof. L. Douglas Smoot

Department of Chemical Engineering

435T Crabtree Technology Building

Brigham Young University

Provo, Utah 84602

Mr. Scott M. Smouse

NETL

P.O. Box 10940

Pittsburgh, PA 15236-0940
Dr. Peter Solomon

Advanced Fuel Research

P.O. Box 18343

East Hartford, CT 6108

Dr. John Stringer

Executive Technical Fellow

Electric Power Research Institute

3412 Hillview Avenue

Palo Alto, CA 94303

Dr. David A.Tillman

Foster Wheeler Development Corporation

Perryville Corporate Park

Clinton, NJ 08809-4000

Dr. Chris Verrill

Research Chemical Engineer

Westvaco Corporation

PO Box 118005

Charleston, SC 29423-8005

Mr. Dave Waltzman

US Department of Energy

Denver Regional Support Office

1617 Cole Boulevard

Golden, CO 80401

Mr. Larry Watson

Chevron Research \& Technology

100 Chevron Way

Richmond, CA 94802

Prof. Jost O. L. Wendt

Dept. of Chemical Engineering

University of Arizona

Tucson, AZ 85721

Dr. Rick Wessel

McDermott Technologies Inc.

1562 Beeson St.

Alliance, $\mathrm{OH} 44601$ 
DISTRIBUTION: (continued)

Prof. Judy Wornat

Dept. of Mech. \& Aerospace Engr.

Princeton University

Princeton, NJ 08544-5263

Mr. Warren Zurn

DOE Atlanta Support Office

730 Peachtree Street NE Suite 876

Atlanta, GA 30308

Dr. Franscisco Domingues Alves de Sousa Instituto de Pesquisas Tecnologicas do

Estado de Sao Paulo - IPT

Cidade Universitaria - CEP 05508-901

Sao Paulo-SP, Brazil

Dr. Javier Ballester

University of Zaragoza

María Zayas, $12,5^{\circ} \mathrm{A}$

50015-Zaragoza

Spain

Professor Tony Bridgwater

Chem. Eng. And Appl. Chem.

Aston University

Aston Triangle

Birmingham B4 7ET

United Kingdom

Dr. Mark Douglas

A/Group Leader, $\mathrm{CO} 2$ Abatement

CANMET Energy Technology Center

1 Haanel Drive

Nepean, ON K1A 1M1

Canada

Professor Kim Dam-Johansen

Hempel's Marine Paints A/S

Lundtoftevej 150

DK-2800 Lyngby

Denmark
Mr. John Gifford

Project Leader, Energy

Forest Research

Private Bag 3020

Rotorua

New Zealand

Dr. Alexandre J. Grebenkov

Head of Laboratory

Institute of Power Engineering Problems

Sonsy, 220109

Minsk

Belarus

Dr. Steven Gust

Fortum

Technology Centre

P.O. Box 310

FIN-06101

Porvoo, Finland

Prof. Klaus R. G. Hein

Universität Stuttgart

Pfaffenwaldring 23

7000 Stuttgart 80

GERMANY

Prof. Hermann Hofbauer

Institut fur Verfahrenstechnik

Brennstofftechnik und Umwelttechnik

Getreidmarkt 9

A-1060 Wien

Austria

Dr. Patrick Hughes

Natural Resources - Canada

CANMET

1 Haanel Drive

Nepean, Ontario

Canada K1A-1M1 
DISTRIBUTION: (continued)

Prof. Mikko Hupa

Åbo Akademi University

Lemminkäisenkatu 14-18 B

FIN-20520 Åbo/Turku

Finland

Prof. Johan Hustad

SINTEF Thermal Energy and

Fluid Machinery

7034 Trondheim

Norway

Dr. Jun Inumaru

Central Research Institute

of Elec. Power Ind.

2-6-1 Nagasaka, YOKOSUKA 240-01

Japan

Dr. Tommy Jacobon

Fortum Power and Heat $\mathrm{Oy}$

POB 20, 00048

FORTUM, Finland

Mr. Henrik Houmann Jakobsen

DK-Teknik

Gladsaxe Mollevej 15

DK-2860 Soborg

Denmark

Mr. Kauko Janka

Kværner Pulping Oy

Kelloportinkatu 1 D

Box 109

Tampere, FIN+33101

Finland

Dr. Helle Junker

Elsamprojekt A/S Power Station

Engineering

53 Kraftvaerksvej

DK-7000 Fredericia

Denmark
Dr. Jaap Koppejan

TNO Institute of Environmental Sciences

Dept. of Thermal Conversion Technology

P.O. Box 342

7300 AH Apeldoorn

The Netherlands

Dr. Alexander A. Mikhalevich

Academy of Sciences, Belarus

Institute of Power Engineeing Problems

IPEP, SOSNY

Russia

Dr. Thomas Nussbaumer

Verenum

Langmauerstrasse 109

CH-8006 Zurich

Switzerland

Dr. Ingwald Obernberger

Institute of Chemical Engineering

Technical University of Graz

Inffeldgasse 25

A-8010 Graz

Austria

Dr. Aksel Olsen

Risoe National Laboratory

Optics \& Fluid Dynamics Dept.

P.O. Box 49 - Bldg. OFD-201

Frederiksborgvej 399

DK-400 Roskilde

Denmark

Mr. Heikki Oravainen

VTT Energy

Fuels and Combustion

P.O. Box 1603

FIN-40101-Jyvaskyla

Finland 
DISTRIBUTION: (continued)

Dr. Niranjan Patel

ETSU, B156

Harwell

OXON OX11 ORA

UNITED KINGDOM

Prof. Dimos Poulikakos

Swiss Federal Institute of Technology

Institute for Energy Technology

ETH-Zentrum

CH-8092 Zürich

Switzerland

Mr. Erik Rensfelt

TPS Termiska Processer AB

Studsvik S-611 82 Nykoping

Sweden

Mr. Joe Robert

CANMET

580 Booth Street- $13^{\text {th }}$ Floor

Ottavwa, Ontario K1A 0E4

Canada

Dr. Yves Schenkel

Chef de travaux-Section Biomass

Head-Biomass Unit

CRA-Departement Genie rural

Chee de Namur, 146

B-5030 Gembloux

Belgium

Dr. Oyvind Skreiberg

Institutt for Termisk Energi og Vannkraft

Fakultet for Maskinteknikk

NTNU, 7491 Trondeim

Norway

Dr. Yrjo Solantausta

VTT Energy

PO Box 1610

FIN-0244 VTT, ESPOO

Finland
Mr. Frans Sulilatu

TNO-MEP, Dep. Combustion Conversion

P.O. Box 342

NL-7300 AH Apeldorn

Netherlands

Dr. Raj Thamburaj

Director, Research and Development

Orenda Aerospace Corporation

3160 Derry Road East

Mississauga, Ontario L4T 1A9

Canada

Professor Honghi Tran

Department of Chemical Engieering \& Applied Chemistry

University of Toronto

200 College Street

Toronto, Canada M4S 1A4

Mr. John Tustin

Forest Research

Private Bag 3020

Rotorua

New Zealand

Mr. Sjaak van Loo

TNO, PO Box 342

NL-7300 AH Apeldoorn

The Netherlands

Prof. Terry Wall

University of Newcastle

Rankin Drive

Newcastle 2308

NSW

Australia

Prof. Franz Winter

Technische Universität Wien

Institut Fuer Verfahrenstechnik

A-1060 Wien

Austria 
DISTRIBUTION: (continued)
MS0750 D. J. Borns, 6116
MS0741 S. G. Varnado, 6200
MS0703 T. R. Mancini, 6216
MS9001 M.E. John, 8000
Attn: 8100 J. Vitko
8400 D. Hensen
8700 M. Dyer
8900 K. Washington
MS9105 B. Wu, 8119
MS9054 W. J. McLean, 8300
Attn: $\quad 8350$ F. Tully
8351 L. Rahn
8356 R. Gallagher
8360 R. Carling
8362 J. Keller
8901 T. Bramlette
MS9052 L. L. Baxter, 8361 (10)
MS9052 D. R. Hardesty, 8361(13)
MS9052 T. Lind. 8361
MS9052 G. Sclippa, 8361
MS9052 C. R. Shaddix, 8361
MS9051 A. E. Lutz, 8362
MS9053 P. Walsh, 8366
MS9403 J. Wang, 8723
Attn: N. Yang

MS9042 M. Perra, 8728

Attn: S. Griffiths

W. Houf

R. Larson

R. Nilson

MS9018 Central Technical Files, 8940-2 (3)

MS0899 Technical Library, 4916

MS9021 Technical Communications

Department, 8528/Technical Library, MS 0899, 4916

MS9021 Technical Communications

Department, 8528 for DOE/OSTI 
This page intentionally left blank 